\title{
Color-Tuned Perovskite Films Prepared for Efficient Solar Cell Applications
}

Dong Cui, Zhou Yang, * Dong Yang, Xiaodong Ren, Yucheng Liu, Qingbo Wei, Haibo

Fan, Jinghui Zeng, Shengzhong(Frank) Liu*

Key Laboratory of Applied Surface and Colloid Chemistry, National Ministry of

Education; Institute for Advanced Energy Materials, School of Materials Science \&

Engineering, Shaanxi Normal University, Xi'an 710062, China

AUTHOR INFORMATION

Corresponding Author

* Prof. Shengzhong (Frank) Liu, E-mail: liusz@snnu.edu.cn; Tel: +86-029-81530785

Dr. Zhou Yang, E-mail: zyang@snnu.edu.cn, Tel: +86-029-81530709

Prof. Shengzhong (Frank) Liu also works at Dalian Institute of Chemical Physics,

National Laboratory for Clean Energy, Chinese Academy of Sciences, Dalian, 116023,

China 


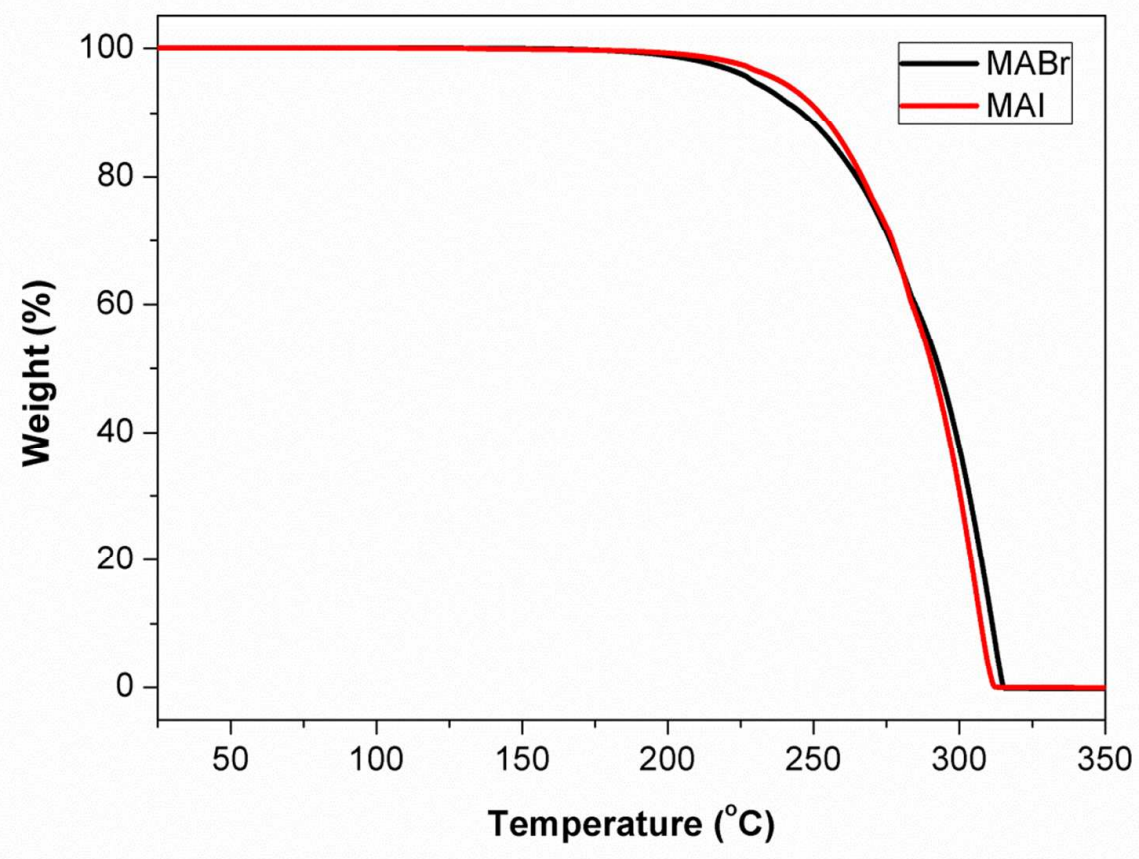

Figure S1. The TGA curve for MAI and MABr powders. 


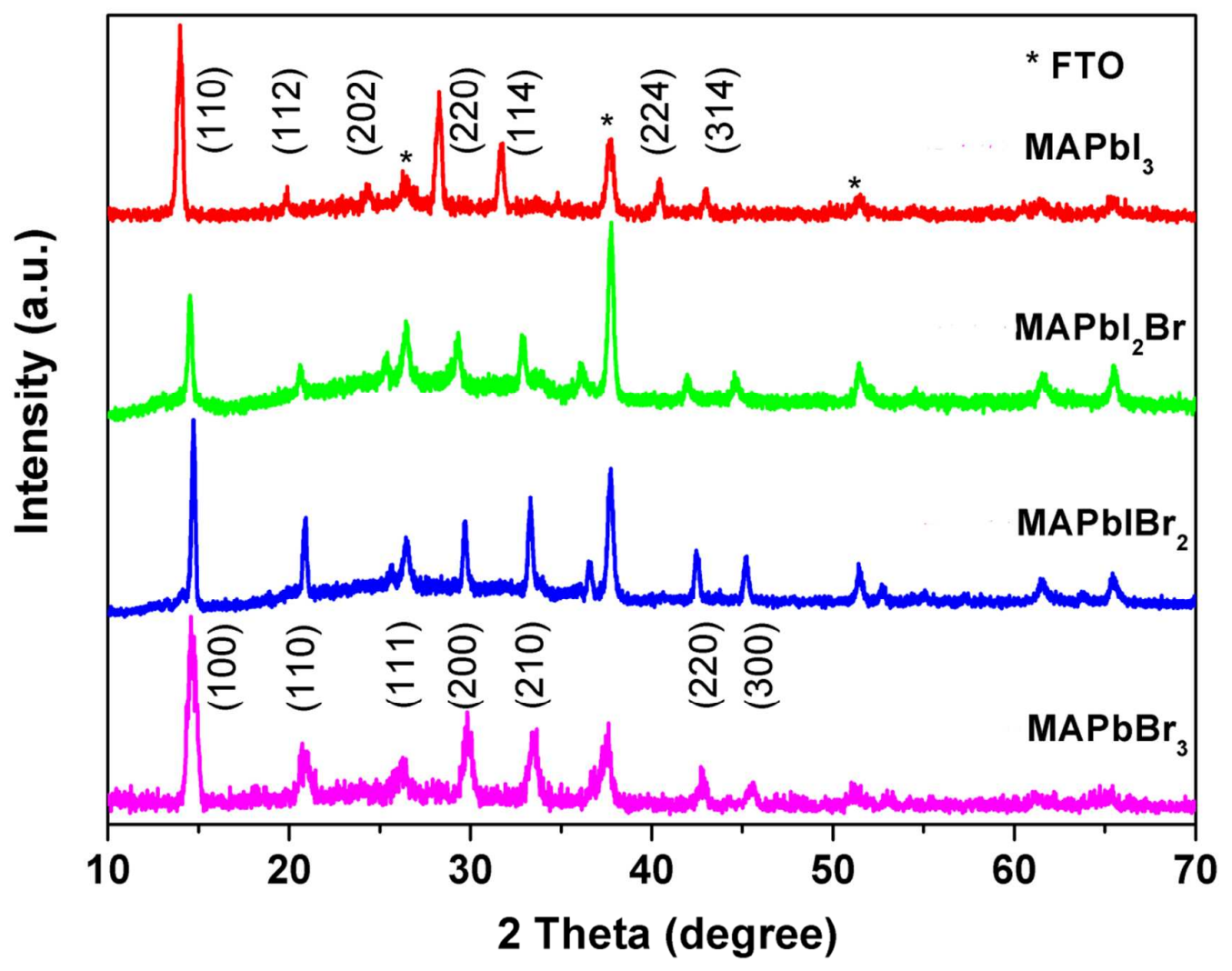

Figure S2. The XRD diffraction patterns of perovskite film with different compositio, including (a) $\mathrm{MAPbI}_{3}$, (b) $\mathrm{MAPbBrI}_{2}$, (c) $\mathrm{MAPbBr}_{2} \mathrm{I}$ and (d) $\mathrm{MAPbBr}_{3}$. 

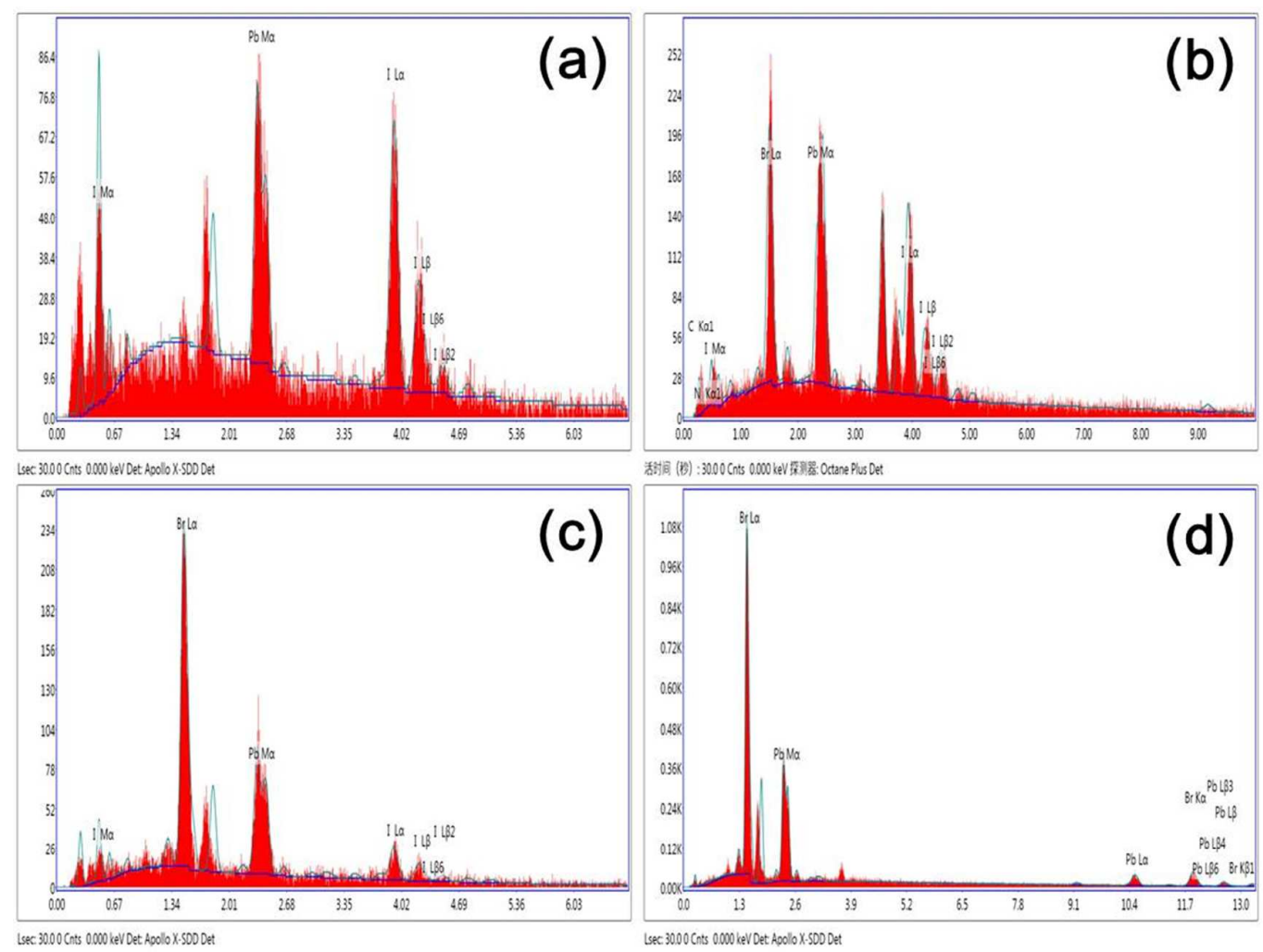

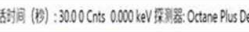

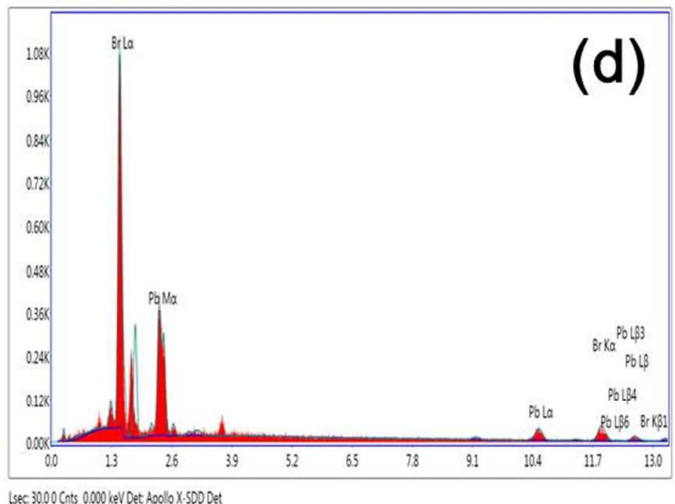

Figure S3. The EDAX data obtained from samples of (a) $\mathrm{MAPbI}_{3}$, (b) $\mathrm{MAPbBrI}_{2}$, (c) $\mathrm{MAPbBr}_{2} \mathrm{I}$ and (d) $\mathrm{MAPbBr}_{3}$. 
Table S1. The eZAF smart quant results of the four perovskite films by EDX measurement.

\begin{tabular}{lllllll}
\hline & & Weight & Atomic & \multicolumn{3}{c}{ Error } \\
& & $(\%)$ & $(\%)$ & & $(\%)$ & \\
\hline $\mathrm{MAPbI}_{3}$ & $\mathrm{~Pb} \mathrm{M}$ & 26.63 & 18.19 & 40.11 & 9.02 & 0.24 \\
& $\mathrm{I} \mathrm{L}$ & 73.37 & 81.81 & 48.23 & 16.13 & 0.73 \\
\hline & $\mathrm{Br} \mathrm{L}$ & 35.73 & 53.11 & 97.35 & 7.30 & 0.31 \\
$\mathrm{MAPbBrI}_{2}$ & $\mathrm{~Pb} \mathrm{M}$ & 36.55 & 20.95 & 50.41 & 10.48 & 0.30 \\
& $\mathrm{I}$ L & 27.72 & 25.94 & 17.23 & 29.53 & 0.26 \\
\hline & $\mathrm{Br} \mathrm{L}$ & 35.73 & 53.11 & 97.35 & 7.30 & 0.31 \\
$\mathrm{MAPbBr}_{2} \mathrm{I}$ & $\mathrm{Pb} \mathrm{M}$ & 36.55 & 20.95 & 50.41 & 10.48 & 0.30 \\
& $\mathrm{I} \mathrm{L}$ & 27.72 & 25.94 & 17.23 & 29.53 & 0.26 \\
\hline $\mathrm{MAPbBr}_{3}$ & $\mathrm{Br} \mathrm{L}$ & 51.01 & 72.97 & 473.09 & 4.54 & 0.41 \\
& $\mathrm{~Pb} \mathrm{M}$ & 48.89 & 27.03 & 247.57 & 6.01 & 0.35 \\
\hline
\end{tabular}




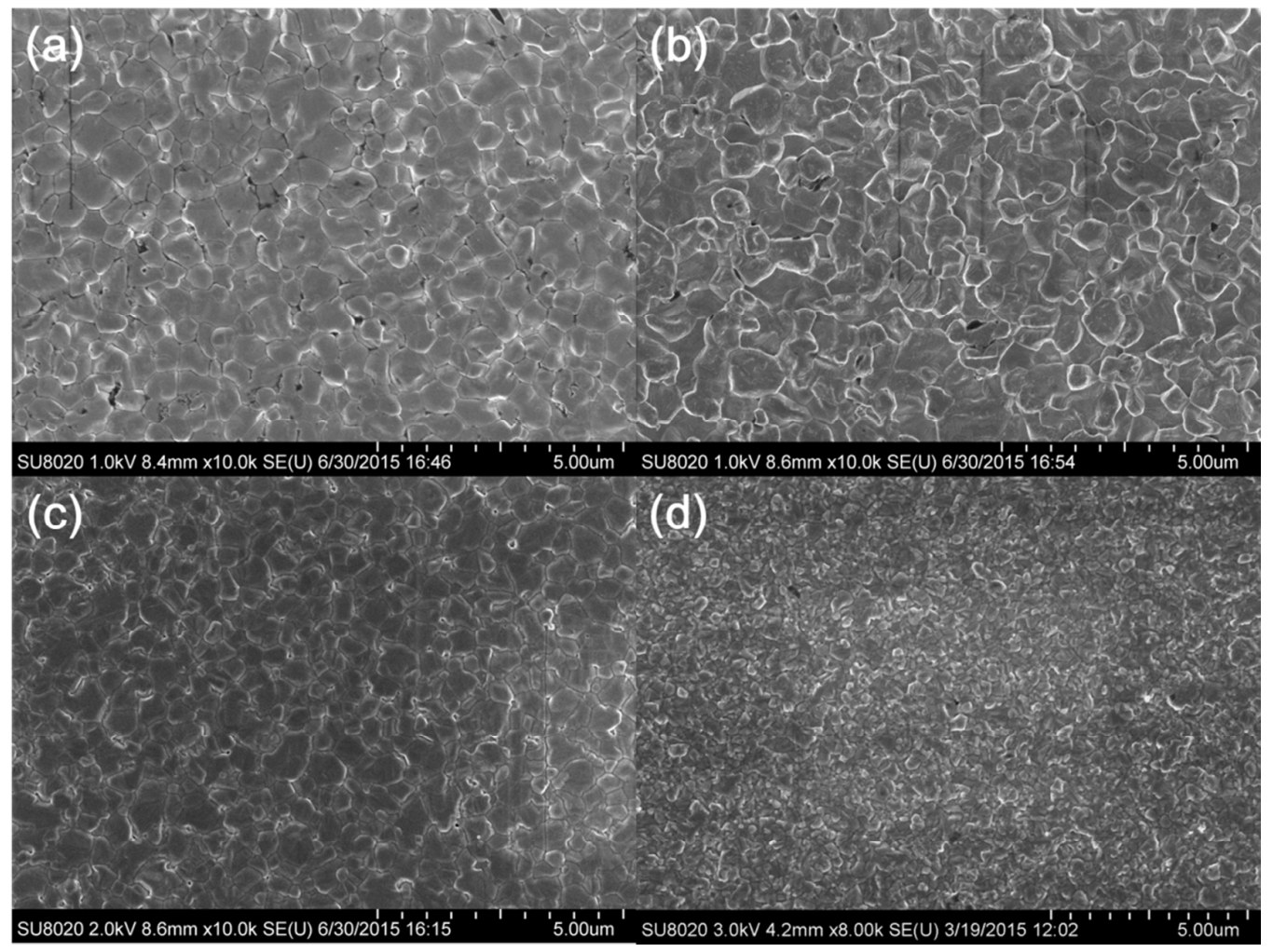

Figure S4. The morphology of perovskite films at low magnification, (a)

$\mathrm{MAPbI}_{3}$, (b) $\mathrm{MAPbBrI}_{2}$, (c) $\mathrm{MAPbBr}_{2} \mathrm{I}$, and (d) $\mathrm{MAPbBr}_{3}$. 